ЯНИЦКИЙ Олег Николаевич - доктор философских наук, профессор; главный научный сотрудник Института социологии ФНИСЦ РАН (117218, Россия, г. Москва, ул. Кржижановского, 24/35, кopn. 5; oleg.yanitsky@yandex.ru)

\title{
РОССИЙСКАЯ АКАДЕМИЯ НАУК КАК СОЦИАЛЬНЫЙ ИНСТИТУТ И ЧЕЛОВЕЧЕСКОЕ СООБЩЕСТВО
}

\begin{abstract}
Аннотация. Опираясь на архивные и частные документы и на собственные исследования методом включенного наблюдения в различных сферах российского и международного научного сообщества за период 1968-2018 гг., автор анализирует отношения в Российской академии наук (АН СССР и РАН) как социальном институте и человеческом сообществе. Анализируются динамика структурно-функциональной организации АН СССР, ее зависимость от развития российского общества и новые вызовы, порожденные цифровой революцией. Автор утверждает, что РАН как социальный институт еще не определил свою позицию по отношению к этой революции. Мобилизация интеллектуального потенциала, развитие международных контактов, поворот в сторону междисциплинарных исследований и сохранение гуманистического потенциала, присущего русской науке, являются сегодня главными вызовами для РАН.

Ключевые слова: академическое сообщество, гуманизм, индивид, производство знаний, социальный институт, структурно-функциональная организация, РАН
\end{abstract}

\section{Введение}

Я работаю в Академии наук уже 50 лет. Если учесть, что члены моей «большой семьи» тоже работали в АН СССР на самых разных должностях - начиная от преподавателя кафедры иностранных языков и до вице-президента АН СССР, то общий стаж работы моей семьи в Академии наук составит почти 250 лет. Жизнь сложилась таким образом, что с детства и затем в течение полувека я имел возможность наблюдать за эволюцией этой организации как сторонний и включенный наблюдатель и участвовать в ее работе как рядовой сотрудник или участник международных и российских исследовательских программ и проектов. Мне представилась также счастливая возможность участвовать также во внепрофессиональной жизни российских ученых (например, санатории или дачные поселки, где жили, работали, отдыхали и общались ученые самых разных специальностей). Командировки в филиалы АН СССР и перманентное участие в ее многочисленных публичных мероприятиях позволяли наблюдать (и фиксировать) существенные стороны динамики этого социального института производства и распространения научных знаний и гуманитарных ценностей.

\section{Задачи и организационная структура АН СССР}

72 года назад в Уставе АН СССР ее роль и задачи были сформулированы следующим образом: «Академия Наук Союза СССР является высшим научным учреждением СССР, объединяющим наиболее выдающихся ученых страны. АН СССР подчинена непосредственно СНК Союза СССР, которому она ежегодно представляет отчет о своей деятельности... Основной задачей АН является всемерное содействие общему подъему теоретических, а также прикладных наук в СССР, изучение и развитие достижений мировой научной мысли». АН СССР пользовалась правами юридического лица, а смета ее расходов включалась в государственный бюджет Союза $\mathrm{CCP}^{1}$.

\footnotetext{
${ }^{1}$ Академия наук СССР: справочник. 1946. М.-Л.: Изд-во АН СССР. С. 287, 289.
} 
Кто же является действительными сотрудниками Академии? «Академия Наук состоит из действительных членов (академиков), почетных членов, членов-корреспондентов и основного штата научных сотрудников, работающих в учреждениях Академии Наук» 1 (здесь и далее - курсив автора. - О.Я.). Значит мы, профессора, доктора и кандидаты наук, а также лаборанты и аспиранты, являемся ее основным штатом.

И далее - не менее принципиально важный, особенно с позиций сегодняшнего дня, пункт: «Основными органами научно-исследовательской работы Академии Наук являются ее научно-исследовательские институты. Институтам предоставляется в пределах утвержденной программы и установленной сметы полная оперативная и хозяйственная самостоятельность. Институты подчинены непосредственно Президиуму. Во главе института стоит директор, управляющий им на правах единоначалия» 2 .

Высшим органом Академии является общее собрание, состоящее из всех ее действительных и почетных членов. Общее собрание устанавливает общие линии научной работы Академии и ее составных частей, решает вопросы организационного характера, заслушивает доклады как филиалов Академии, так и ее отдельных членов, обсуждает проблемы научного и научно-технического характера, избирает почетных членов, действительных членов, президиум Академии и утверждает членов-корреспондентов Академии ${ }^{3}$.

Другим важнейшим пунктом устава АН СССР (особенно в свете современных реалий) является созданный при Академии Совет по изучению природных богатств и производительных сил (СОПС). СОПС ведет широкую исследовательскую и экспедиционную работу по исследованию природных богатств и сил отдельных республик, краев и областей, опираясь на сеть институтов, филиалов и баз Академии и другие научно-исследовательские организации, созывает конференции, обобщает исследовательские работы и содействует практическому использованию их результатов ${ }^{4}$. О СОПСе я знаю не понаслышке, поскольку мой отец был долгое время его сотрудником, ездил от него в экспедиции и т.д. Возникает законный вопрос: зачем было разрушать эту эффективно работающую систему, регулярно и своевременно обеспечивающую страну сведениями о запасах стратегически важных природных ископаемых? Зачем было фактически передавать это общенародное достояние в руки господ капиталистов?

Тот же вопрос касается и филиалов Академии на местах. В течение многих лет, занимаясь социально-экологическими проблемами РФ, я много раз встречался с работниками этих филиалов. К сожалению, многие из них влачат жалкое существование по той же причине приватизации. Оборудование и сами здания опытно-промышленных предприятий распроданы или разворованы, закупленное дорогое импортное оборудование стоит и портится без дела, а сами их сотрудники не имеют ни приличного заработка, ни перспективы научной карьеры.

Далее, один из пунктов устава, имеющий прямое отношение к нам, сотрудникам РАН, гласит: «Руководство редакционно-издательской деятельностью принадлежит Редакционно-издательскому совету, избираемому Общим Собранием». И далее: «Академия Наук имеет право пересылать без цензуры все свои издания за границу; равным образом, покупаемые и выписываемые Академией Наук из-за границы книги и издания также освобождаются от цен-

\footnotetext{
1 Там же. С. 290.

2 Там же. С. 296.

3 Там же. С. 293.

4 Там же. С. 296-297.
} 
зуры. Академия имеет право самостоятельной покупки за границей по соглашению с внешнеторговыми организациями страны ${ }^{1}$. Сегодня мы, сотрудники РАН, не имеем права заказать нужные нам книги, даже за деньги гранта! Несмотря на разрушения и огромные потери в ходе Великой Отечественной войны 1941-1945 гг, АН СССР имела в своем составе «исследовательские институты, библиотеки, музеи, лаборатории, кабинеты и комиссии, а также филиалы и базы на местах» и принимала меры, чтобы все эти учреждения были обеспечены высококвалифицированным научным составом и соответствующим оборудованием. Не прекращались связи с академиями, учеными и научными обществами союзных республик, восстанавливались связи с учеными других стран.

АН СССР занималась также систематической подготовкой научных кадров, для чего была создана аспирантура АН СССР. Одновременно велась систематическая работа по повышению квалификации научных кадров всей страны, в частности посредством организации циклов лекций и докладов и предоставлением молодым ученым мест в своих учреждениях для практических занятий и усовершенствования знаний ${ }^{2}$.

Одновременно возобновилась работа лечебно-оздоровительного и клубного комплекса Академии. Дома ученых в Москве и Ленинграде оказывали всемерную поддержку ученым по самым разным направлениям: это библиотека, помещения для научных семинаров и встреч, общих собраний АН СССР и концертной деятельности, а также для кружковых занятий подростков.

Даже в годы «большого террора» все время поддерживалась связь ученых с научно-технической и культурной средой страны. Многочисленные экспедиции, работа Комиссии по изучению естественных производительных сил (КЕПС, позже преобразованная в СОПС), экспедиции по исследованию Арктики не могли бы существовать без тесного взаимодействия ученых с профессионалами многих других специальностей. Но были и тесные культурные связи. Как же удалось в столь короткие сроки восстановить работу этой сложной организационной структуры? Во-первых, во главе Академии стояли не просто кабинетные ученые, а ученые, обладавшие недюжинными организационными способностями. Во-вторых, благодаря ответственности и напряженному труду всего персонала АН СССР. В 1941-1943 гг. я жил в интернате АН СССР под Казанью, где о нас, детях, заботились жены и сестры ученых. Так что российская традиция патронажной и благотворительной помощи сохранялась. В-третьих, ученые АН СССР были не только материально обеспечены, но и система медицинского обслуживания была намного лучше, чем сегодня. В-четвертых, после окончания ВОВ правительство построило всем действительным членам Академии комфортабельные дачи в пригородах Москвы и Ленинграда, а потом и вблизи других городов страны.

\section{Наша наука как социальное сообщество}

Речь не идет о спорадических контактах научных работников на конгрессах и конференциях, когда обсуждать проблемы, представляющие взаимный интерес, некогда, но выпить чашку кофе всегда приятно. Не идет и речь о регулярных служебных контактах в ходе работы над совместными исследовательскими проектами. Это - наша рутина.

Здесь я имею в виду межличностное общение ученых между собой вне института науки (напомню заповедь В. Вернадского: всегда надо быть в «гуще

\footnotetext{
1 Там же. С. 295, 298.

2 Там же. С. 289.
} 
жизни»). Вот маленькая интеллектуальная загадка, которую я обычно задавал своим коллегам, когда встречался с ними в «Узком» или другом благословенном месте. Вот она: что первым делом сделал Вернадский, приехав на отдых в «Узкое» в конце 1930-х гг.? Вот типичные ответы моих уважаемых коллег: осмотрел отведенный ему номер, разобрал вещи, пошел к врачу и т.п. Нет! Вернадский и на отдыхе оставался ученым. Он затребовал у сестры-хозяйки санатория опись всех отдыхающих в «Узком», переписал его и начал их методичный опрос по собственному сценарию.

Зачем? У великого ученого была своя цель: написать свою историю страны по источникам из первых рук (сегодня это называется методом глубинного полуструктурированного интервью). Вернадский даже начал писать наброски глав ее будущего текста, но, к сожалению, не успел. Но и для нас, рядовых научных работников, такое общение чрезвычайно продуктивно. Почему?

Вокруг наших двух столиц было несколько подобных мест. Помимо санаториев, это были дачные поселки, в т.ч. принадлежавшие Академии наук. И первым из них была Николина Гора, дачный поселок работников науки и искусства под Москвой, созданный по их же инициативе в 1928 г. В чем было преимущество его и ему подобных? В них временно или постоянно жили разные по профессии и темпераменту интеллектуалы, и их общение между собой давало синергетический эффект. Но и сама атмосфера (люди, природа, неспешный ритм жизни) была предпосылкой межличностных контактов.

Вот как-то в «Узком» к нам, группе гуманитариев, подошел известный создатель новейшей ракетной техники академик С.П. Непобедимый и сказал: «Какие у вас интересные разговоры! Позвольте, я к вам присоединюсь». А вечером на скамейке у входа в санаторий собирался сход (мы его в шутку называли Клубом знаменитых капитанов), среди которых были академик Д.С. Лихачев, Е.П. Челышев и много других очень интересных людей, что тоже часто давало синергетический интеллектуальный эффект. Разве я мог себе представить, что в течение нескольких лет смогу задавать интересующие меня вопросы двум Нобелевским лауреатам - академику В.Л. Гинзбургу и А.М. Прохорову! Кстати, именно Прохоров обратил мое внимание на факт экспоненциального разрастания ведомственной науки: по его мнению, в конце 1970-х гг. только $2 \%$ совокупного научного потенциала было сосредоточено в Академии наук CCCP.

Ученый всегда остается ученым. Когда другой Нобелевский лауреат, академик П.Л. Капица был смещен Сталиным со всех своих постов, ученый устроил на своей даче на Николиной Горе мастерскую, где смог (хотя бы частично) реализовать часть своих инженерных замыслов. Позже он напишет в своей книге, что изобретатель иногда важнее теоретика, поскольку изобретатель может своими руками «соединить несоединимое» [Капица 1981]. В ходе таких, казалось бы, дачных контактов достигалось не просто доверие, но и взаимопонимание представителей естественных, гуманитарных и технических дисциплин. Плюс знания соединялись с умением.

\section{Противоречивые тренды}

Россия, и не только она одна, находится сегодня в переходном периоде. 3. Бауман вслед за А. Грамши так его и обозначил - interregnum. Этим латинским термином Бауман назвал некоторое «промежуточное состояние», когда прежние средства человеческой деятельности перестают работать, а новые, более эффективные, как предполагалось, средства все еще находятся в процессе разработки или, в лучшем случае, - в процессе экспериментальной проверки. В результате возникает двойное рассогласование - временно́е (диахроническое) 
и пространственное, синхронное. Называя это состояние «переходным», «мы тем самым говорим о временно́м отрезке неизвестной нам продолжительности между существующей ситуацией, по-прежнему идущей своим курсом, и той, которая еще не сложилась, но которая, как мы предполагаем, заменит со временем существующую ситуацию» [Bauman 2017: 119].

Но в работах этих двух ученых речь шла, выражаясь классическим языком марксистской философии, о переходе от одного способа производства общества к другому. Причем предполагалось, что новый способ производства, в конечном счете, полностью вытеснит старый. Однако в жизни оказалось все сложнее. Сам этот переходный период внутренне противоречив, конфликтен, это своего рода Тяни-Толкай, только в глобальном масштабе. Тренд всеобщей универсализации и «транснационализации» периодически сменяется возвратными движениями к укреплению национальных государств, возвратом части индустриального производства из стран «третьего мира» в метрополию и т.П. Наиболее яркий пример такого противоречивого течения глобализации демонстрируют США и ее лидер Д. Трамп.

Но для массы населения РФ задача еще сложнее. С одной стороны, требуется ускоренный «переход на цифру», с другой - откуда взять то огромное количество кадров высокой специализации, необходимой для переподготовки десятков миллионов человек? Одно дело - умение пользоваться личными гаджетами, и совсем другое - освоение новейших систем программирования и их конструирования. С одной стороны, миллионы людей старшего возраста, занятые в сфере ручного труда, будут вынуждены продолжить работу в связи с повышением пенсионного возраста. С другой стороны, никто их на работу в сферу «цифровой экономики и политики» не возьмет - их ум уже не так гибок. А освоить и запомнить многочисленные протоколы, правила и коды тем более непросто. Значит, снова поденная работа, случайные заработки и в перспективе - мизерная пенсия.

Неизбежно возникнут трудности и культурного порядка. Вся цифровая экономика и политика построена на английском сленге весьма специфического свойства. Его придется не только осваивать в срочном порядке, но и научиться мыслить в его терминах и категориях. Даже людям (в основном среднего и пожилого возраста), которые никогда не знали английского языка, придется выучить этот «цифровой английский». Это социокультурный барьер, преодолеть который далеко не всем под силу. Достаточно посмотреть, как люди мучаются с кодами и другими сложностями при элементарной операции снятия денег с карточки или при оплате коммунальных услуг. А за их спиной маячат хакеры и просто мелкие жулики, которые под видом оказания помощи старикам их просто грабят. Старые люди по-прежнему очень доверчивы, и это еще один потенциальный риск для их кармана и имущества. Эти люди и так в массе своей одиноки и часто вынуждены искать помощи у других. Но даже если речь идет о людях среднего возраста (30-45 лет), то и они начинают ощущать психологический барьер и отчуждение от подростков и молодежи.

У молодежи - свои проблемы «переходного периода». Они сейчас выходят на рынок труда, но он неумолимо сокращается под воздействием роботизации. Однако главная из них состоит в том, что средняя школа все больше отстает от жизни, которая становится все более быстрой и интегрированной, а процесс обучения все еще построен по классно-урочному принципу, т.е. по сугубо монодисциплинарному: физика, химия, математика и т.д. И наш институт среднего образования сопротивляется любым попыткам преодоления этого монодисциплинарного барьера. К тому же именно в среде школьников периодически возникают различные способы психологического унижения и насилия над более 
слабыми учениками: групповой буллинг, кибербуллинг, моббинг, хейзинг и т.д. Роль учебника жизни берут на себя улица и социальные сети.

\section{Выводы}

Пока РАН как социальный институт, за исключением нескольких многопрофильных центров, движется по «инерционной» (монодисциплинарной) траектории. Размежевание между дисциплинами продолжает углубляться, в то время как практика «переходного периода» требует комплексных и процессуальных решений. И руководство РАН в этом повинно лишь частично. За последние 20-25 лет РАН стала одной из множества российских академий и исследовательских вузов, которые обладают более высоким, чем РАН, кадровым потенциалом и материально-техническим обеспечением. РАН также утратила свою лидирующую роль «кузницы научных кадров» и распространителя научных знаний во всем обществе.

Пора научно сопоставить приобретения и потери от тотальной цифровизации, и прежде всего в отношении человека. Не делает ли она его не только более «одномерным», но и зависимым от новых технологий? Не утеряет ли он такие качества, как находчивость, изобретательность и мастеровитость, присущие русской культуре? Не слишком ли «цифровая экономика» сократит количество и качество среднего класса как основы нашего общества?

Восстановление своего лидерства в уже начавшийся «переходный период» РАН может осуществить только посредством мобилизации и консолидации своих интеллектуальных сил и материальных ресурсов и развития междисциплинарных исследований. Но для этого ученые должны размышлять, экспериментировать, дискутировать с коллегами, иметь удобные площадки для общения, а не бегать в поисках случайного заработка. Уметь не только практически применять, но и продвигать на мировую арену достижения нашей науки. И главное - прежде чем передать дело в руки специалистов «по цифре», подумать, не утеряем ли мы в этом «технократическом порыве» великую роль русской науки как хранителя гуманистической ориентации и транслятора ее будущим поколениям?

\section{Список литературы}

Капица П.Л. 1981. Эксперимент, теория, практика. М.: Наука. 495 с.

Bauman Z. 2017. A Chronicle of Crisis: 2011-2016. London, UK: Social Europe Edition. 163 p.

\section{RUSSIAN ACADEMY OF SCIENCES AS SOCIAL INSTITUTION AND HUMAN COMMUNITY}

Abstract. Drawing on the archives, human documents and on the author's inclusive observations in various sociocultural milieus of Russian and international intellectual community in the 1968-2018, the article analyzes the relationships in Russian Academy of Sciences (Academy of Sciences of the USSR and RAS) as social institution and human community. Development of structural-functional organization of academic community, its dependence on the evolution of Russian society, and new challenges to the RAS created by digital revolution are considered. The author states that this institute has not yet define its attitude toward digital revolution and its social consequences. He believes that a mobilization of intellectual potential of the 
RAS, the maintenance of international contacts, a decisive turn to interdisciplinary methods of analysis, and protection of humanistic stand inherent to Russian science throughout its history are the main challenges to the RAS.

Keywords: academic community, humanism, individual, knowledge production, science, social institution, structuralfunctional organization, Russian Academy of Sciences

ПОСУХОВА Оксана Юрьевна - кандидат социологических наук, доцент; доцент Южного федерального университета (344006, Россия, г. Ростов-на-Дону, ул. Б. Садовая, 105/42, оф. 506-а; belloks@yandex.ru)

\title{
РОЛЬ ПРОФЕССИОНАЛЬНЫХ ДИНАСТИЙ В АКАДЕМИЧЕСКОЙ СРЕДЕ РОССИЙСКОГО ОБЩЕСТВА
}

\begin{abstract}
Аннотация. Академические династии являются одним из институтов воспроизводства и развития научной деятельности, их можно рассматривать как носители интеллектуального и символического капитала. Вместе с тем роль профессиональных династий в академической среде может оцениваться двояко. Конструктивность академических династий проявляется в социализации молодого поколения, создании профессионального фона не только для членов династии, но и для других и становится при этом ядром успешно действующих научных коллективов. Династии также могут рассматриваться как носители стандартов профессионализма, обеспечивающие устойчивое развитие научной среды. Но династия может представлять собой не только механизм преемственности научной деятельности, но и монополию, которая способствует возникновению фильтров, закрытости научного сообщества, что говорит о ее деструктивном потенциале.
\end{abstract}

Ключевые слова: академическая династия, профессионализм, монополия, ресурсы, символический капитал

П рофессиональные династии в академической среде неоднозначно воспринимаются в российском обществе. С одной стороны, сохраняется высокий авторитет академического сообщества как носителя культуры и знаний, с другой - еще в предшествующий советский период сложился стереотип о неприятии династийности в обществе, где официально пропагандировался образ рабочих династий [Ткач 2007].

В советском обществе ученые занимали устойчивое место в должностной иерархии: им гарантировались значительные бонусы в виде материальных и символических льгот ${ }^{1}$. Факторами, определяющими академическую карьеру, были талант ученого и одновременно его лояльность по отношению к партии и государству. Временами академическая среда демонстрировала принципиальность в отборе кандидатов в академическое сообщество (отклонение кандидатур партийных деятелей, например, С.П. Трапезникова) [Кривоносов 2004: 169]. Принципиальная позиция академического сообщества, которая вызывала неудовольствие и раздражение партийных структур, заключалась в том, чтобы не руководствоваться в подборе академических кадров никакими критериями, кроме профессионализма и преданности науке. Этос академического сообщества был ориентирован на корпоративизм, на введение в механизм карьерных регуляторов авторитета, заслуг, солидарности. Вместе с тем академическое карьерное пространство как совокупность позиций, установок и отношений в рамках построения карьеры не исключало и неформальный механизм [Млечин 2018].

\footnotetext{
${ }^{1}$ Торгашев В.А. Вспоминая СССР. Доступ: https://nstarikov.ru/blog/23233 (проверено 08.07.2018).
} 